\title{
A sensitivity study using maximum entropy to interpret SANS data from the Ringhals Unit 3 NPP
}

DOI:

10.1016/j.jnucmat.2018.07.027

\section{Document Version}

Accepted author manuscript

Link to publication record in Manchester Research Explorer

\section{Citation for published version (APA):}

Hyde, J. M., Boothby, R. M., Swan, H., Riddle, N., Wilford, K., Burke, M. G., \& Efsing, P. (2018). A sensitivity study using maximum entropy to interpret SANS data from the Ringhals Unit 3 NPP. Journal of Nuclear Materials, 509, 417-424. https://doi.org/10.1016/j.jnucmat.2018.07.027

\section{Published in:}

Journal of Nuclear Materials

\section{Citing this paper}

Please note that where the full-text provided on Manchester Research Explorer is the Author Accepted Manuscript or Proof version this may differ from the final Published version. If citing, it is advised that you check and use the publisher's definitive version.

\section{General rights}

Copyright and moral rights for the publications made accessible in the Research Explorer are retained by the authors and/or other copyright owners and it is a condition of accessing publications that users recognise and abide by the legal requirements associated with these rights.

\section{Takedown policy}

If you believe that this document breaches copyright please refer to the University of Manchester's Takedown Procedures [http://man.ac.uk/04Y6Bo] or contact uml.scholarlycommunications@manchester.ac.uk providing relevant details, so we can investigate your claim.

\section{OPEN ACCESS}




\section{A sensitivity study using maximum entropy to interpret SANS data from the Ringhals Unit 3 NPP}

\section{J.M. Hyde ${ }^{\mathrm{a}, \mathrm{c}, \text { * }}$}

jonathan.hyde@materials.ox.ac.uk

\section{R.M. Boothby \\ H. Swan \\ N. Riddle \\ K. Wilford ${ }^{\mathrm{b}}$ \\ M.G. Burke \\ P. Efsing ${ }^{\mathrm{d}}$}

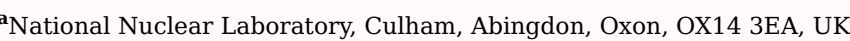

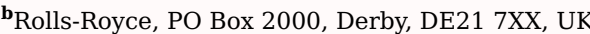

'School of Materials, University of Manchester, Manchester, M13 9PL, UK

dVattenfall Ringhals AB, Väröbacka, Sweden

${ }^{*}$ Corresponding author. National Nuclear Laboratory, Culham, Abingdon, Oxon, OX14 3EA, UK.

Abstract

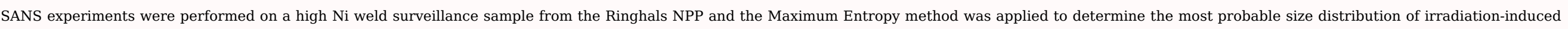

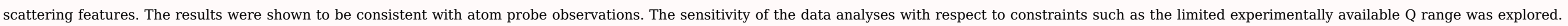

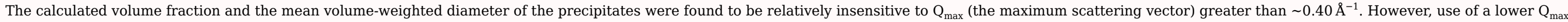

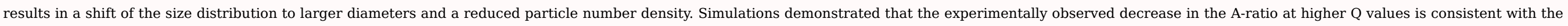
presence of vacancies or higher Mn contents in smaller features. Importantly, features which are experimentally unresolvable do not add to the apparent volume fraction of the features which are resolved.

Keywords: Reactor pressure vessel steels; Small angle neutron scattering; Maximum entropy

\section{Introduction}

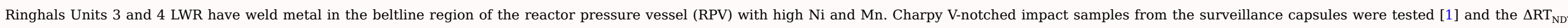

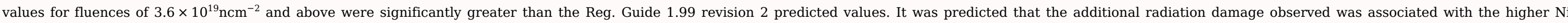

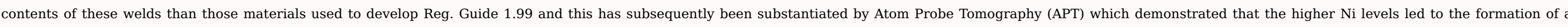

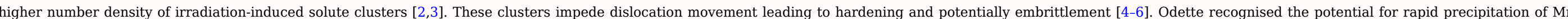

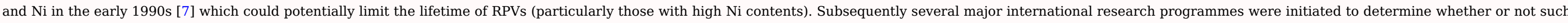

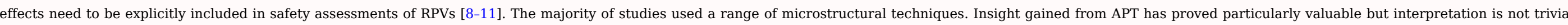

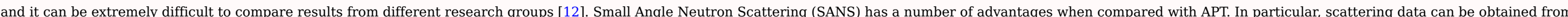




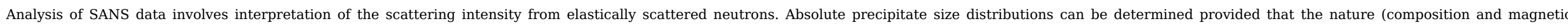

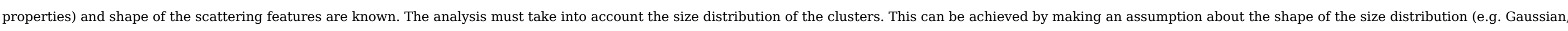

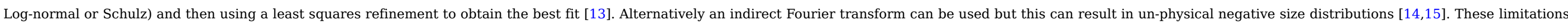

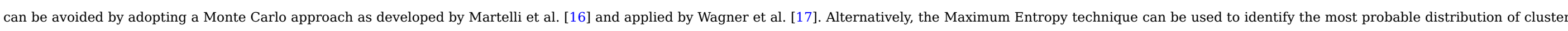

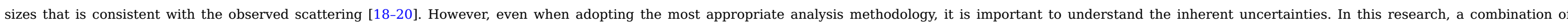
experimental SANS data obtained from a surveillance sample of Ringhals R3 NPP and modelling has been used to examine-:

- The effect of the $Q$-range over which SANS data are fitted using the maximum entropy program on the resulting particle size distribution.

- The effect of assuming the presence of two different types of cluster.

- The effect of "unresolvable" (typically assumed to be sub-10 $\AA$ diameter) features on the size distribution returned by maximum entropy fitting.

The results are compared with previously published APT data [3] on the same material condition.

\section{Experimental details}

\subsection{SANS experiments}

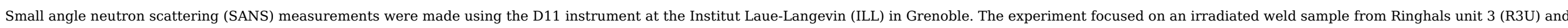
a corresponding unirradiated reference sample. The irradiation history and nominal compositions of the weld metals are given in Table 1.

Table 1 Nominal compositions of Ringhals 3 high Ni welds (at.\%).

\begin{tabular}{|c|c|c|c|c|c|c|c|c|c|c|c|c|c|}
\hline Weld & Post-Weld Stress-Relief Treatment & Irradiation Conditions $\left(\mathrm{n} / \mathrm{cm}^{2}\right) \mathrm{E}>1 \mathrm{MeV}$ & $\mathrm{C}$ & $\mathrm{Ni}$ & Mn & $\mathrm{Cr}$ & $\mathrm{Si}$ & $\mathrm{Cu}$ & Mo & $\mathrm{Al}$ & $\mathrm{P}$ & $\mathrm{S}$ & $\mathrm{N}$ \\
\hline Unit 3 & $575^{\circ} \mathrm{C}$ for $26 \mathrm{~h} ; 630^{\circ} \mathrm{C}$ for $30 \mathrm{~h}$; furnace cooled & $5.6 \times 10^{19 a}\left(\mathrm{~T}_{\text {irr }}=284^{\circ} \mathrm{C}\right)$ & 0.24 & 1.50 & 1.48 & 0.08 & 0.42 & 0.07 & 0.29 & 0.06 & 0.02 & 0.01 & 0.05 \\
\hline
\end{tabular}

a The highest dose in the capsule is $6.26 \times 10^{19} \mathrm{ncm}^{-2}$, but the sample used in this work was extracted from the centre layer which had an estimated fluence of $5.6 \times 10^{19} \mathrm{ncm}-2$.

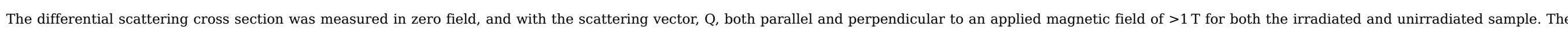

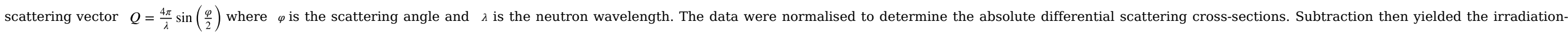
induced component of the differential scattering cross section, $\left(\frac{d \sigma}{d \Omega}\right)_{S}$.

The macroscopic coherent neutron scattering cross-section $\left(\mathrm{cm}^{-1}\right.$ steradian $\left.{ }^{-1}\right)$ for a dilute concentration of a distribution of spherical precipitates with varying diameters is given by:

$$
\left(\frac{d \Sigma}{d \Omega}\right)_{S}=N_{S}\left(\frac{d \sigma}{d \Omega}\right)_{S}=[N+\gamma M] \int C(D) \cdot V(D) \cdot\left|F_{D}(Q)\right|^{2} d D
$$

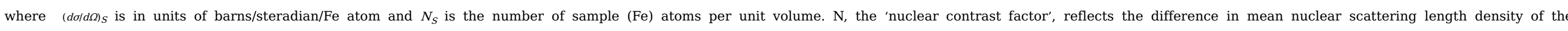

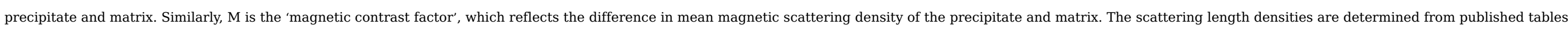

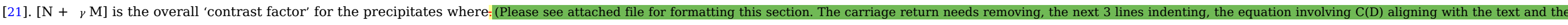
equation involving Vf aligning with the text.)

$y$ is the contribution from the magnetic contrast: 


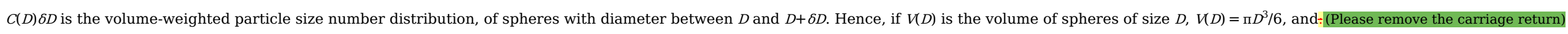
$C(D)=V(D) \cdot N(D)$

where $N(D) \delta D$ is the particle size number distribution, of spheres with diameter between $D$ and $D+\delta D$.

$\left|F_{D}(Q)\right|$ is the form factor for spherical precipitates of diameter $D$, which is given by:

$\left|F_{D}(Q)\right|=\left[\frac{24[\sin (Q D / 2)-(Q D / 2) \cos (Q D / 2)]}{Q^{3} D^{3}}\right]$

The total volume fraction of precipitates in the sample is given by=(Please remove the carriage return and add a full stop after the equation for $\mathrm{V}_{\mathrm{f}}$.) $V_{f}=\int C(D) d D$

The A-ratio, defined as $\frac{(d \sigma / d \Omega)_{\perp}}{(d \sigma / d \Omega)_{/ /}}=\frac{N+M}{N}$ provides information on the chemical composition of the scattering features.

\subsection{Simulated data}

Simulated SANS data may be generated by calculating scattering cross-sections as a function of $Q$ for a given size distribution of particles of known contrast by numerically integrating the expression $[N+\gamma M] \int C(D) \cdot V(D) \cdot\left|F_{D}(Q)\right|^{2} d D$

Numerical integrations were performed, using the assumption that the nuclear and magnetic contrast originate from the same scatterers:

- For each value of $Q$, the form factor $\left|F_{D}(Q)\right|$ was calculated for discrete values of particle diameter at $2.5 \AA$ intervals.

- The scattering cross-section at each discrete particle diameter $D$ was then calculated as $[\mathrm{N}+\gamma \mathrm{M}] \cdot V_{f(D)}\left(\pi D^{3} / 6\right) \cdot\left|F_{D}(Q)\right|^{2}$, where $V_{f(D)}$ is the absolute volume fraction of particles in the size bin centred at $D$.

- The total scattering cross-section at each value of $Q$ was then determined by summing the cross-sections across all particle diameters.

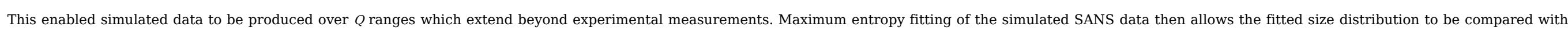

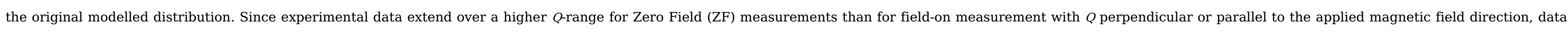
simulations have generally been made for $\mathrm{ZF}(\gamma=2 / 3)$ conditions.

\subsection{Maximum entropy analyses}

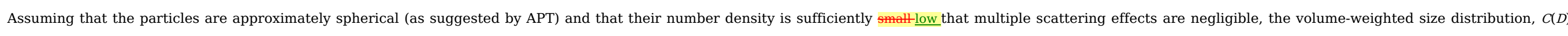

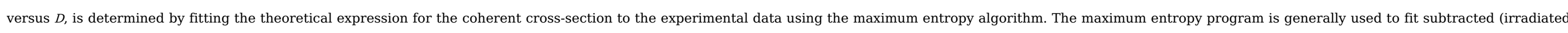
sample - unirradiated control sample) data files corresponding to the irradiation-induced coherent scattering component.

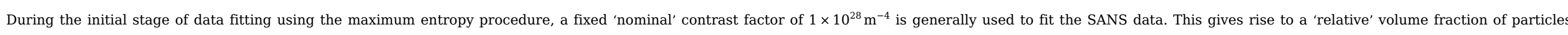


which is related to the absolute volume fraction and the true contrast factor by:

Rel. $V_{f} \times($ nominal contrast factor $)=$ Absolute $V_{f} \times($ true contrast factor $)$

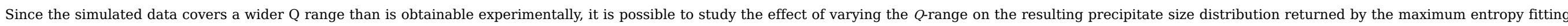
program. Two approaches were adopted.

- by curtailing experimental data

- by using simulated data to extend the $Q$-range beyond that for which experimental measurements have been made

\section{Results}

\subsection{Analysis of SANS data}

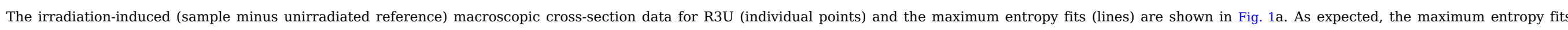

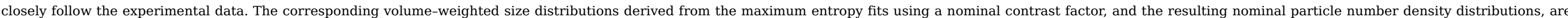
given in Fig. 1b.
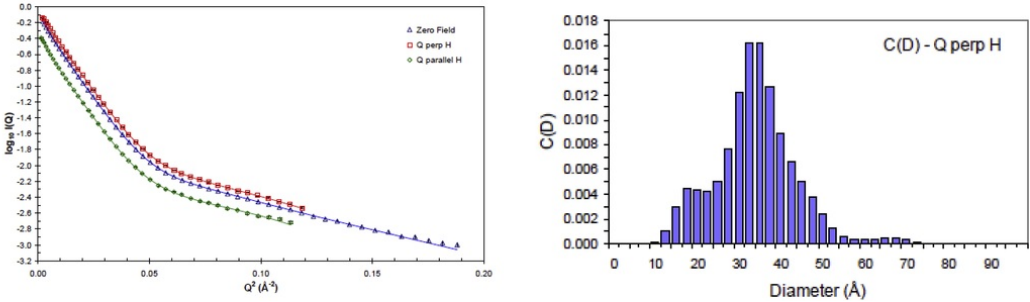

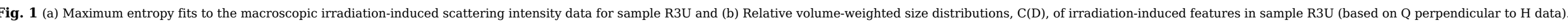
alt-text: Fig. 1

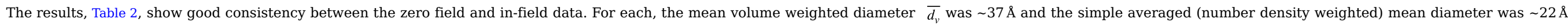
The volume weighted results are consistent with previously reported APT data [3] on this material condition (35 $\pm 1 \AA)$.

Table 2 Relative volume fractions, mean volume and number density weighted diameters, and mean A-ratios of irradiation-induced features and previously reported APT data. alt-text: Table 2

Sample SANS Data

APT data [3]

\begin{tabular}{|c|c|c|c|c|c|c|c|c|c|c|c|c|}
\hline & & & & & & & & & & & \\
\hline & \multicolumn{3}{|c|}{ Zero Field } & \multicolumn{3}{|c|}{ Q perp H } & \multicolumn{3}{|c|}{ Q parallel H } & \multirow[t]{2}{*}{ A-ratio } & & \\
\hline & $V_{f}^{R e l}$ & $\overline{d_{v}}(\AA)$ & $\overline{d_{n}}(\AA)$ & $V_{f}^{R e l}$ & $\overline{d_{v}}(\AA)$ & $\overline{d_{n}}(\AA)$ & $V_{f}^{R e l}$ & $\overline{d_{v}}(\AA)$ & $\overline{d_{n}}(\AA)$ & & $\overline{d_{v}}(\AA)$ & $V_{f}^{A b .}$ \\
\hline R3U & 0.249 & 37 & 22 & 0.297 & 36 & 25 & 0.143 & 37 & 22 & 2.1 & $35 \pm 1$ & 0.014 \\
\hline
\end{tabular}

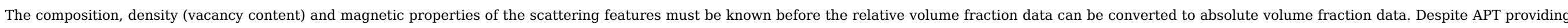

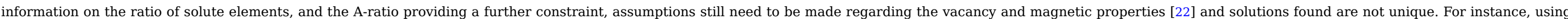

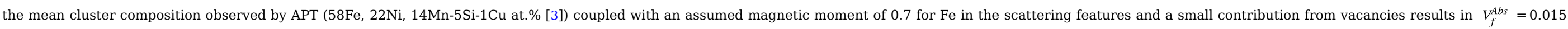

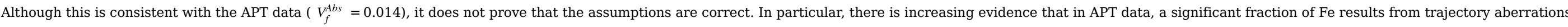

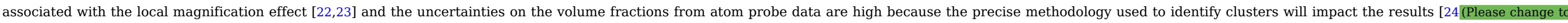




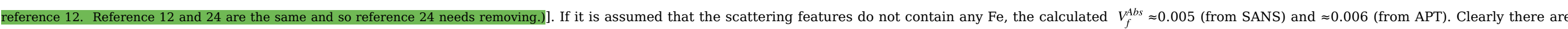

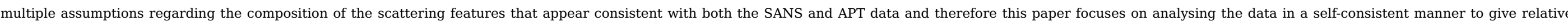
volume fractions.

\section{Discussion}

\subsection{Effect of the Q-range}

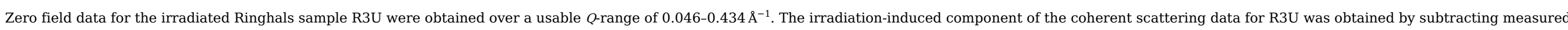

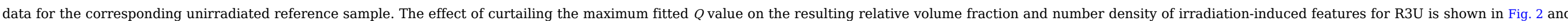
is summarised in Table 3 .

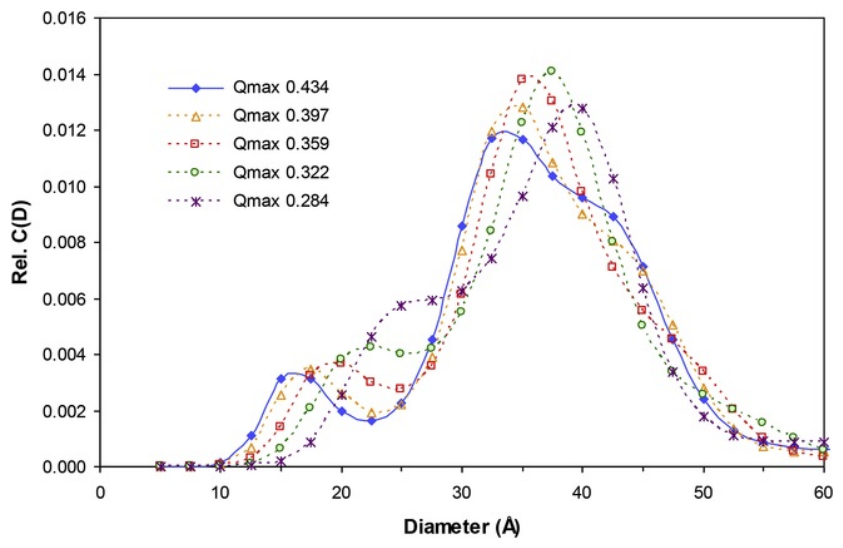

Fig. 2 Effect of curtailing $\mathrm{Q}_{\max }$ on relative volume-weighted size distribution, $C(D)$ of irradiation-induced features in Ringhals sample R3U.

alt-text: Fig. 2

Table 3 Effect of curtailing $Q_{\max }$ on relative volume fraction and number density of irradiation-induced features in Ringhals sample R3U. alt-text: Table 3

\begin{tabular}{|c|c|c|c|c|}
\hline$Q_{\max }\left(\AA^{-1}\right)$ & Rel. Vf (ZF contrast) & $\bar{D}_{V}(\AA)$ & Rel. $N_{d}^{\mathrm{a}}\left(10^{24} \mathrm{~m}^{-3}\right)$ & $\bar{D}_{N}(\AA)$ \\
\hline 0.434 & 0.2488 & 36.7 & 21.9 & 22.2 \\
\hline 0.397 & 0.2480 & 36.8 & 20.5 & 23.1 \\
\hline 0.359 & 0.2465 & 37.0 & 18.2 & 24.6 \\
\hline 0.322 & 0.2447 & 37.2 & 16.3 & 26.1 \\
\hline 0.284 & 0.2427 & 37.4 & 14.5 & 27.7 \\
\hline
\end{tabular}

${ }^{\text {a }}$ Rel. $N_{d}$ is the total number density summed over each size bin and is based on the nominal SANS contrast factor of $1 \times 10^{-28} \mathrm{~m}^{-4}$ used in the maximum entropy fitting program.

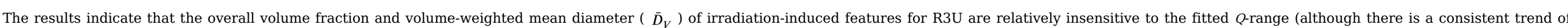

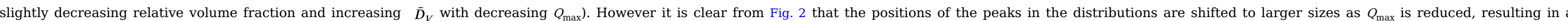
significant reduction in the apparent feature number density (Rel. $N_{d}$ - for which the nominal units are $10^{24} \mathrm{~m}^{-3}$ ) and a corresponding increase in the number-weighted mean diameter ( $\bar{D}_{N}$ ). 


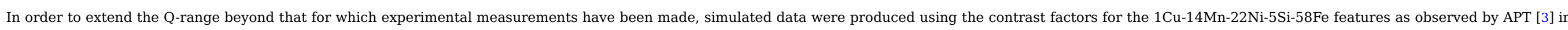

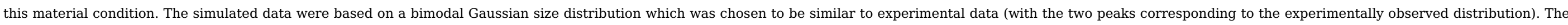

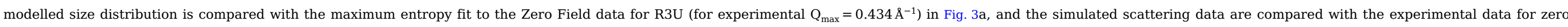

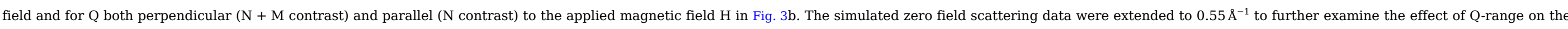
real space size distribution returned by the maximum entropy fitting procedure.

a)

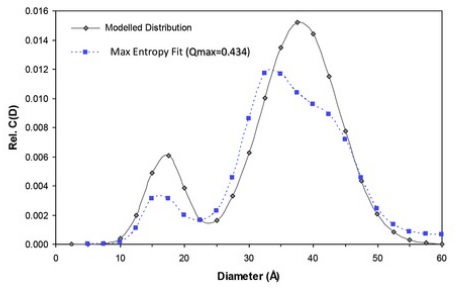

b)

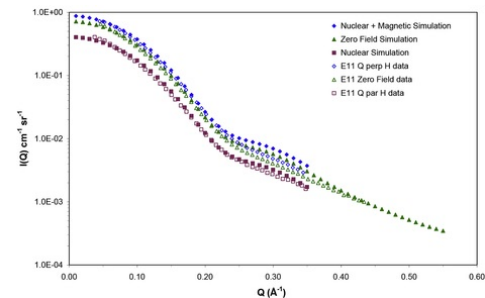

Fig. 3 Comparison of (a) relative volume-weighted size distribution, $C(D)$ and (b) simulated macroscopic scattering intensity data for sample R3U and modelled distribution.

\section{alt-text: Fig. 3}

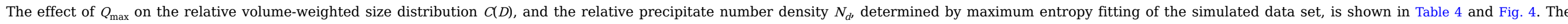

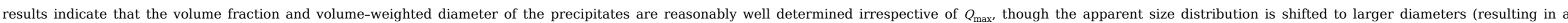
reduction in number density and an increase in the number-weighted mean diameter) as $Q_{\max }$ is reduced below $\sim 0.40 \AA^{-1}$.

Table 4 Effect of curtailing $Q_{\max }$ on relative volume fraction, mean diameter and number density of features in simulated zero field data set.

\section{alt-text: Table 4}

\begin{tabular}{|c|c|c|c|c|}
\hline$Q_{\max }\left(\AA^{-1}\right)$ & Rel. Vf (ZF contrast) & $\bar{D}_{V}(\AA)$ & Rel. $N_{d}^{\mathrm{a}}\left(10^{24} \mathrm{~m}^{-3}\right)$ & $\bar{D}_{N}(\AA)$ \\
\hline 0.55 & 0.2738 & 34.5 & 31.2 & 21.2 \\
\hline 0.50 & 0.2738 & 34.5 & 31.1 & 21.3 \\
\hline 0.45 & 0.2740 & 34.5 & 31.3 & 21.2 \\
\hline 0.40 & 0.2738 & 34.5 & 30.8 & 21.3 \\
\hline 0.35 & 0.2719 & 34.8 & 26.7 & 22.9 \\
\hline 0.30 & 0.2671 & 35.3 & 20.9 & 25.7 \\
\hline Modelled Distribution\# & 0.2756 & 34.5 & 31.8 & 21.0 \\
\hline
\end{tabular}

${ }^{\text {a }}$ Rel. $N_{d}$ is the total number density summed over each size bin and is based on the nominal SANS contrast factor of $1 \times 10^{-28} \mathrm{~m}^{-4}$ used in the maximum entropy fitting program. 


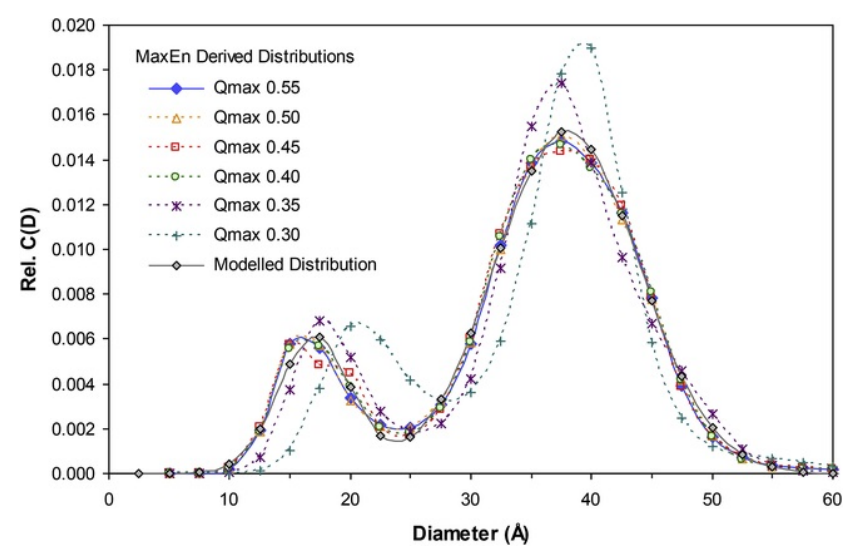

Fig. 4 Effect of curtailing $Q_{\max }$ on the relative volume-weighted size distribution, $C(D)$, and number density, $N_{d^{\prime}}$ of features in simulated zero field data set.

\section{alt-text: Fig. 4}

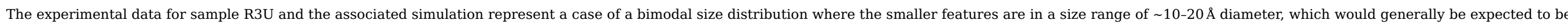

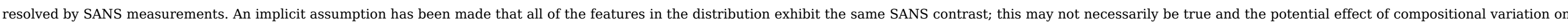
the apparent size distribution is considered next.

\subsection{Effect of assuming the presence of two different types of cluster}

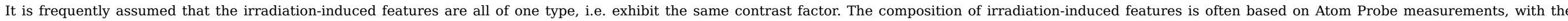

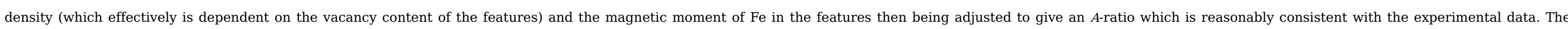

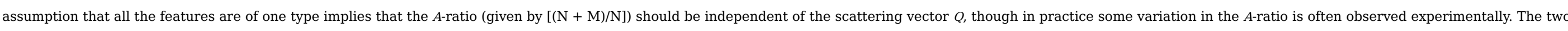

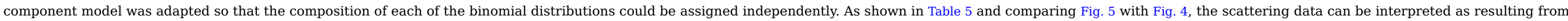
a lower number density (or volume fraction) of higher contrast features or a higher number density of lower contrast features.

Table 5 SANS contrast factors of different types of $\mathrm{Cu}-\mathrm{Mn}$-Ni-Si-Fe precipitates.

\begin{tabular}{|c|c|c|c|c|c|c|c|c|c|}
\hline \multirow[t]{2}{*}{ Ppt type } & \multicolumn{5}{|c|}{ Solute Content (at.\%) } & \multirow[t]{2}{*}{ Magnetic moment of $\mathrm{Fe}$ in feature } & \multirow[t]{2}{*}{ Density $\left(\mathrm{g} \mathrm{cm}^{-3}\right)$} & \multicolumn{2}{|c|}{$A$-ratio } \\
\hline & $\mathrm{Cu}$ & $\mathrm{Mn}$ & $\mathrm{Ni}$ & $\mathrm{Si}$ & $\mathrm{Fe}$ & & & & \\
\hline A (main peak at $\sim 35-40 \AA$ ) & 1 & 14 & 22 & 5 & 58 & 0.7 & 6.0 & 2.17 & 15.3 \\
\hline $\mathrm{D}$ (minor peak at $\sim 15 \AA$ ) & 5 & 26 & 22 & 5 & 42 & 0.7 & 5.0 & 1.65 & 31.4 \\
\hline
\end{tabular}




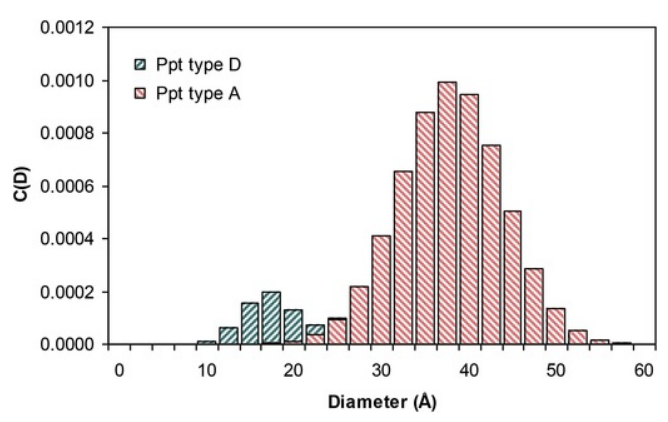

Fig. 5 Volume-weighted size distributions, $C(D)$ of bimodal model data which exhibit the same total coherent, zero field, neutron scattering cross-sections as shown in Fig. 1a.

alt-text: Fig. 5

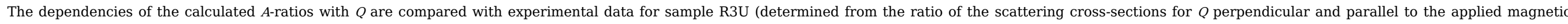

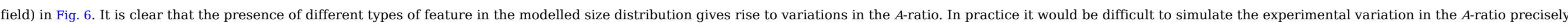

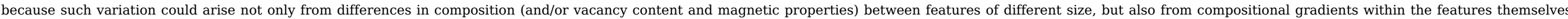

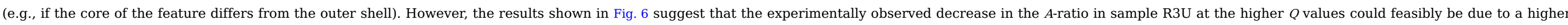
vacancy and Mn content in the smaller features detected by SANS.

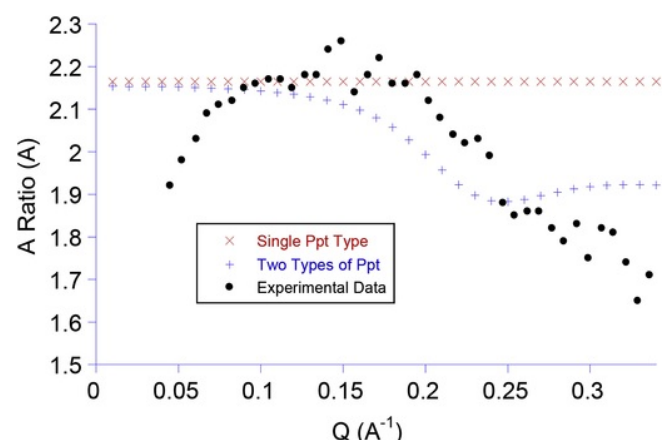

Fig. 6 Comparison of calculated A-ratios for modelled bimodal size distributions containing different types of feature with experimentally determined A-ratio for Ringhals sample R3U.

\section{alt-text: Fig. 6}

\subsection{Effect of "unresolvable" (sub-10 $\AA$ diameter) features on the size distribution returned by maximum entropy fitting}

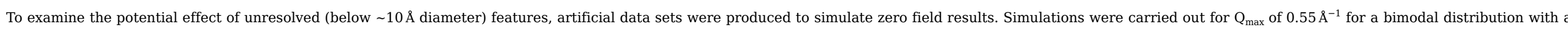
small peak, centred at $7 \AA$ (Rel. $\left.V_{f}=0.0257\right)$, overlapping a larger peak centred at $14 \AA$ (Rel. $V_{f}=0.2573$ ) (Fig. 7). In this case the smaller peak was not resolved by the maximum entropy fit. 


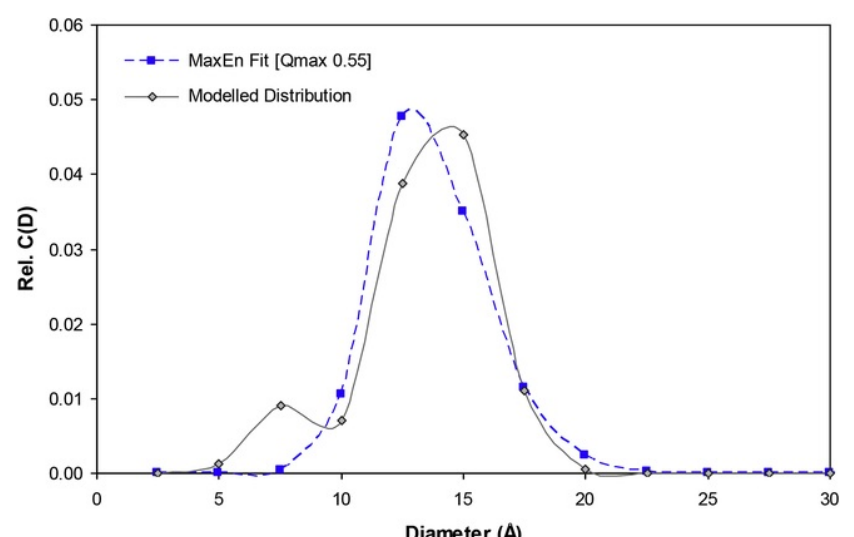

Fig. 7 Comparison of relative volume-weighted size distributions, $C(D)$, of features derived from maximum entropy fitting with modelled bimodal distributions.

\section{alt-text: Fig. 7}

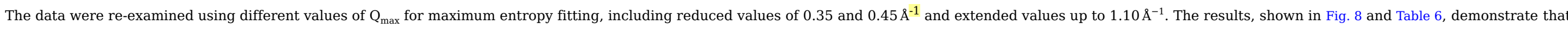

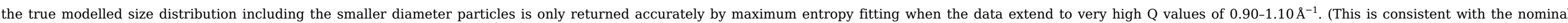

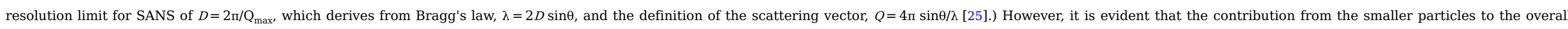

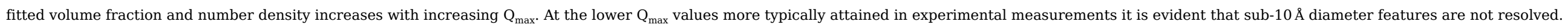

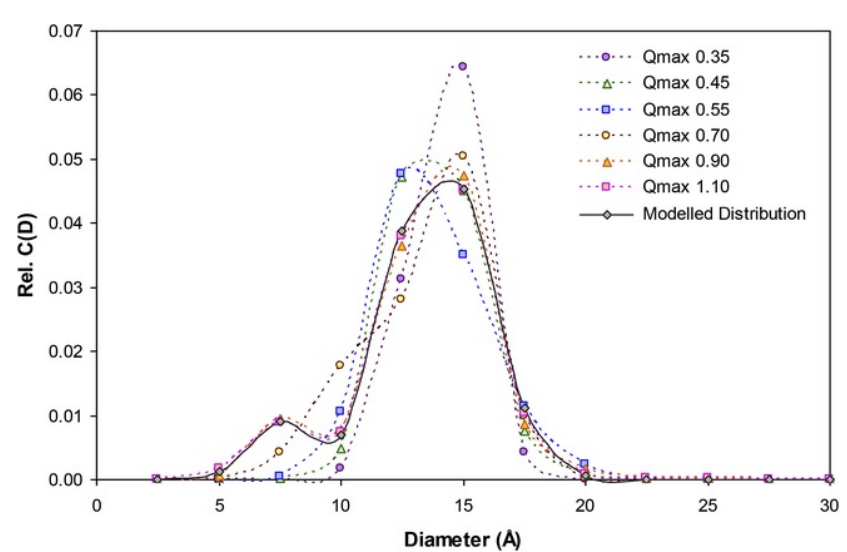

Fig. 8 Effect of $Q_{\max }$ on the relative volume-weighted size distribution, $C(D)$ of features in simulated zero field data.

\section{alt-text: Fig. 8}

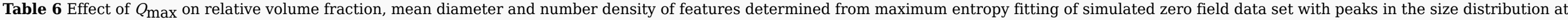
$D_{V}=7 \& 14 \AA$ (with corresponding Rel. $\mathrm{V}_{\mathrm{f}}=0.0257 \& 0.2573$ ).

\begin{tabular}{|c|c|c|c|c|c|}
\hline$Q_{\max }\left(\AA^{-1}\right)$ & Rel. $V_{f}$ (ZF contrast) & $\bar{D}_{V}(\AA)$ & Rel. $N_{d}^{\mathrm{a}}\left(10^{24} \mathrm{~m}^{-3}\right)$ & $\bar{D}_{N}(\AA)$ & Smaller features resolved? \\
\hline 0.35 & 0.2539 & 14.2 & 180 & 13.7 & No \\
\hline 0.45 & 0.2654 & 13.9 & 211 & 13.1 & No \\
\hline
\end{tabular}




\begin{tabular}{|c|c|c|c|c|c|}
\hline 0.55 & 0.2692 & 13.8 & 232 & 12.5 & No \\
\hline 0.70 & 0.2774 & 13.5 & 283 & 11.0 & Partially \\
\hline 0.90 & 0.2809 & 13.4 & 335 & 10.7 & Yes \\
\hline 1.10 & 0.2816 & 13.4 & 367 & 10.1 & Yes \\
\hline Modelled Distributiona & 0.2830 & 13.4 & 358 & 10.3 & \\
\hline
\end{tabular}

${ }^{\text {a Rel. }} N_{d}$ is the total number density summed over each size bin and is based on the nominal SANS contrast factor of $1 \times 10^{-28} \mathrm{~m}^{-4}$ which is used in the maximum entropy fitting program.

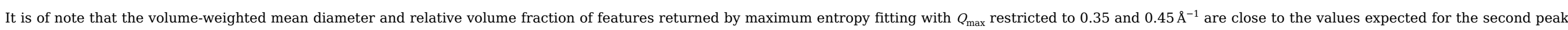

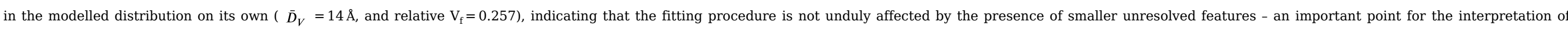
experimental data.

\section{Conclusions}

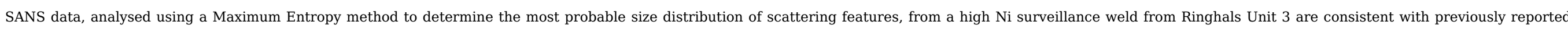

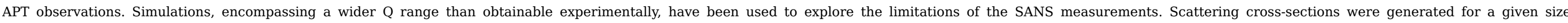

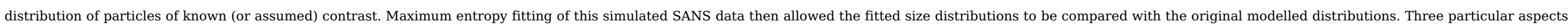
relating to the interpretation of experimental SANS measurements have been examined:

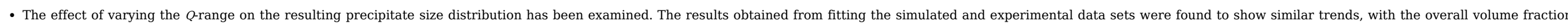

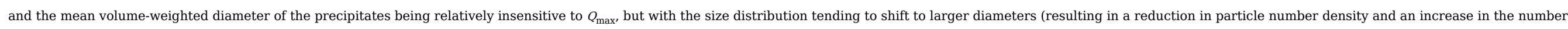
weighted mean diameter) as the fitted $Q_{\max }$ is reduced below $\sim 0.40 \AA^{-1}$.

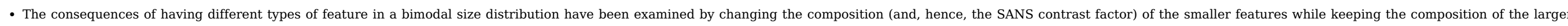

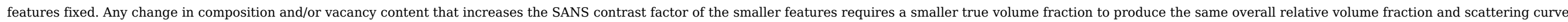

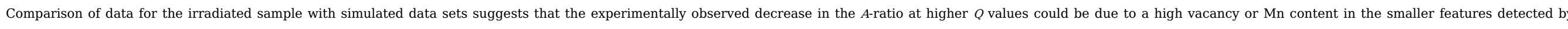
SANS.

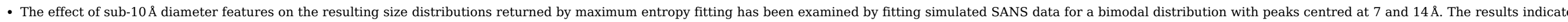

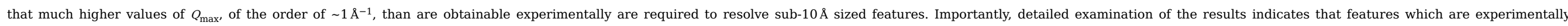
unresolvable do not add to the apparent volume fraction of the features which are resolved.

\section{Data availability}

The raw/processed data required to reproduce these findings cannot be shared at this time as the data also forms part of an ongoing study.

\section{Acknowledgements}

The authors would like to acknowledge Dr P. Lindner (ILL) for his support and guidance performing the experimental measurements at the Institut Laue Langevin.

\section{References}

[1] P. Efsing, C.Jansson, T. Mager and G. Embring, J. ASTM Int. (JAI), Vol. 4, No. 7 Paper ID JAI100719 (www.astm.org).

[2] M.K. Miller, K.A. Powers, R.K. Nanstad and P. Efsing, J. Nucl. Mater. 437, 2013, 107-115.

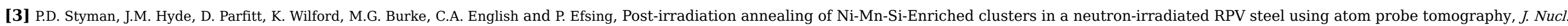


Mater. 459, April 2015, 127-134.

[4] W.J. Phythian and C.A. English, J. Nucl. Mater. 205, 1993, 162.

[5] K.C. Russell and L.M. Brown, Acta Metall. 20, 1972, 969-974.

[6] C.A. English and J.M. Hyde, Radiation damage of reactor pressure vessel steels, In: R. Konings, (Ed), Comprehensive Nuclear Material, 2012 , Elsevier, ISBN: 9780080560274.

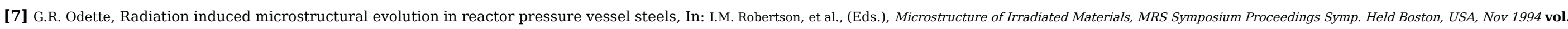
373, 1995, Materials Research Society; Pittsburgh, 137-148.

[8] E. Altstadt, E. Keim, H. Hein, M. Serrano, F. Bergner, H.-W. Viehrig, A. Ballesteros, R. Chaouadi and K. Wilford, Nucl. Eng. Des. 278, $2014,753-757$.

[9] M.K. Miller, K.F. Russell, J. Kocik and E. Keilova, J. Nucl. Mater. 282, 2000, 83-88.

[10] T. Takeuchi, A. Kuramoto, J. Kameda, T. Toyama, Y. Nagai, M. Hasegawa, T. Ohkubo, T. Yoshiie, Y. Nishiyama and K. Onizawa, J. Nucl. Mater. 402, 2010, 93-101.

[11] P.B. Wells, T. Yamamoto, B. Miller, T. Milot, J. Cole, Y. Wu and G.R. Odette, Acta Mater. 80, 2014, 205-219.

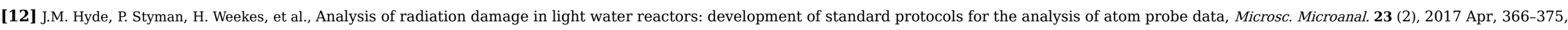
https://doi.org/10.1017/S1431927616012678.

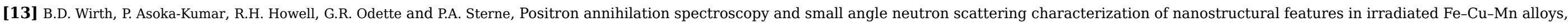
MRS Proc 650, 2001, R6.5.

[14] O. Glatter, Determination of particle-size distribution functions from small angle scattering data by means of the indirect transformation method, J. Appl. Crystallogr. 13, 1980, 7-11.

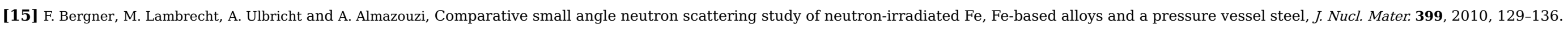

[16] S. Martelli and P.E. di Nunzio, Particle size distribution of nanospheres by Monte Carlo fitting of small angle x-ray scattering curves, Part. Part. Syst. Char. 19, $2002,247-255$.

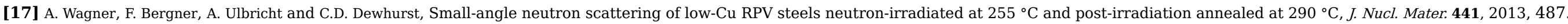

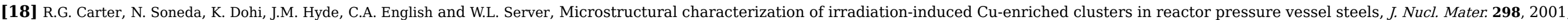
211-224.

[19] J.A. Potton, G.J. Daniell and B.D. Rainford, Particle size distributions from SANS data using the maximum entropy method, J. Appl. Crystallogr. 21, 1988, 663-668.

[20] J.M. Hyde and C.A. English, An analysis of the structure of irradiation induced Cu-enriched clusters in low and high nickel welds, MRS Proc 650, 2001 , R6.6.

[21] www.ncnr.nist.gov/resources/n-lengths/list.html, original reference neutron news, Vol. 3, No. 3, 1992, pp. $29-37$.

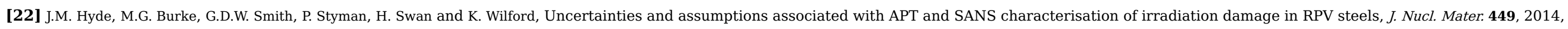
308-314.

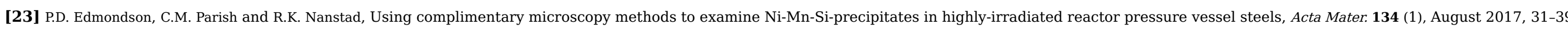

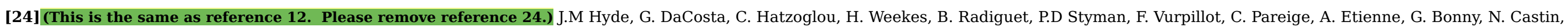
L. Malerba, P. Pareige, Microsc. Microanal., 23(2), 366-375(This is the same as reference 12. Please remove reference 24).

[25] G.D. Wignall, Practical aspects of SANS experiments, section III.1, In: T. Imae, T. Kanaya, M. Furusaka and N. Torikai, (Eds.), Neutrons in Soft Matter, 2011, Wiley. 


\section{Queries and Answers}

Query: Please check the article title, keywords section and correct if necessary.

Answer: Checked

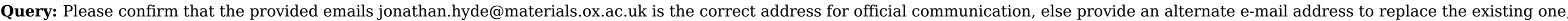
because private e-mail addresses should not be used in articles as the address for communication.

Answer: Confirmed

Query: Please check whether the designated corresponding author and mail id is correct, and amend if necessary.

Answer: Confirmed

Query: Please check the address for the corresponding author that has been added here, and correct if necessary.

Answer: Confirmed

Query: Please check the hierarchy of the section headings and correct if necessary.

Answer: Correct

Query: Please check the headr row and layout of Tables 2, and correct if necessary.

Answer: Correct

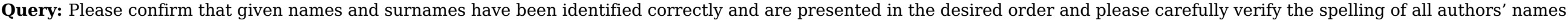
Answer: Yes

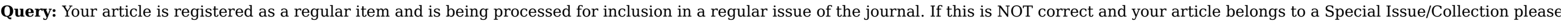
contact v.anand@elsevier.com immediately prior to returning your corrections.

Answer: Yes 